\title{
Gender Equality and E-Scooters: Mind the Gap! A Statistical Analysis of the Sicily Region, Italy
}

\author{
Tiziana Campisi $^{1}\left(\mathbb{D}\right.$, Anastasios Skoufas ${ }^{2}$ D, Alexandros Kaltsidis ${ }^{2}$ and Socrates Basbas $^{3, *(D)}$ \\ 1 Faculty of Engineering and Architecture, Kore University of Enna, Cittadella Universitaria, 94100 Enna, Italy; \\ tiziana.campisi@unikore.it \\ 2 School of Architecture and the Built Environment, KTH Royal Institute of Technology, \\ 11428 Stockholm, Sweden; skoufas@kth.se (A.S.); kalt@kth.se (A.K.) \\ 3 Department of Transportation and Hydraulic Engineering, School of Rural and Surveying Engineering, \\ Aristotle University of Thessaloniki, 54124 Thessaloniki, Greece \\ * Correspondence: smpasmpa@auth.gr
}

Citation: Campisi, Tiziana, Anastasios Skoufas, Alexandros Kaltsidis, and Socrates Basbas. 2021. Gender Equality and E-Scooters: Mind the Gap! A Statistical Analysis of the Sicily Region, Italy. Social Sciences 10: 403. https://doi.org/ 10.3390/socsci10100403

Academic Editor: Andrew Barnfield

Received: 4 September 2021

Accepted: 7 October 2021

Published: 19 October 2021

Publisher's Note: MDPI stays neutra with regard to jurisdictional claims in published maps and institutional affiliations.

Copyright: (c) 2021 by the authors. Licensee MDPI, Basel, Switzerland. This article is an open access article distributed under the terms and conditions of the Creative Commons Attribution (CC BY) license (https:// creativecommons.org/licenses/by/ $4.0 /)$.

\begin{abstract}
Mobility since 2000 has undergone enormous changes due to new modes of transport and related technologies as well as catastrophic and pandemic events. Several strategies have been implemented by European states to mitigate impacts and assess possible risks in a preventive way. Today, mobility pursues the objectives of sustainability and resilience through a series of short-, medium- and long-term strategies that encourage the collaboration of the population to the choices of urban planning and design. Among the different modes of transport that have had a rise in recent years are scooters. Such modes are well suited to connecting spaces within the first and last mile. Similar to other modes of transportation, scooters are also characterized to date by reduced gender equity. The present work investigates through the administration of an online survey the participants' perceptions concerning the factors that most affect this gender balance considering the metropolitan areas of Catania and Palermo in Sicily. The development of an ordinal regression model revealed the most influential factors of the gender equality variable. Specifically, age, job occupation and perceived safety level of micromobility modes play the most important role. The present findings can be effectively utilized in the planning stage of e-scooter services towards the bridging of the gender gap.
\end{abstract}

Keywords: gender gap; mobility equality; e-scooter; sustainable mobility; regression modeling; gender issues in transport

\section{Introduction}

The months following the various pandemic phases of COVID-19 were characterized in Italy by an increase in vehicular traffic in all regions, causing an increase in pollution rates and a growth in road congestion. The pandemic has strongly influenced people's mobility choices and has, in some cases, accentuated the reduced gender equality (Boglietti et al. 2021; González-Sánchez et al. 2021).

Starting in early 2021, European states were to implement drastic measures to reduce car traffic, reclaim public road space and encourage smart and socially distant forms of urban transport.

Already by the end of 2020, the European Community had encouraged the spread of active mobility by encouraging both the redevelopment and design of new cycling and pedestrian infrastructure and by providing the various states with the possibility of providing vouchers for the purchase of electric bikes and micro mobility. The last includes bicycles, scooters, skateboards, Segways and hover-boards, can be human-powered or electric and are either privately owned or shared (Abduljabbar et al. 2021). As far as short-distance travel is concerned (i.e., less than $2 \mathrm{~km}$ ), there has been a strong nationwide demand for electric scooters. To avoid traffic, for small distances within a few miles many 
users may choose to bike or walk, bringing attention to micro-mobility. In the last 5 years, there has been a strong growth in the publication of studies on e-scooters (Raptopoulou et al. 2020; Kostareli et al. 2020). Some research confirms that many people have resorted to using micro mobility to reach their destination in the absence or reduced presence of conventional transportation services such as subways and taxi (Glavić et al. 2021).

During the pandemic phase, public transportation (buses, subways, and ride-sharing services) was rarely available or used because of the potential for on-board contagion or reduced service caused by fewer people on board or reduced frequency of rides.

In this way several service companies have upgraded or included their services for the first time in different cities of Italy, especially strengthening the cities of the central south. For example, the popularity of e-scooters in the Italian capital Rome underlines trends that are occurring worldwide (Tomassi 2018). A significant one is that residents and commuters move by scooter much more than visitors as confirmed by a recent study that found that scooters are used much more for work displacement than for leisure purposes (Carrese et al. 2021).

There has also been an improvement in air quality as e-scooters are replacing car travel. A number of actions have been implemented in different European contexts to improve infrastructure for exclusive or mixed use (cycling and walking), such as the cycle-to-work schemes in the United Kingdom (UK) (Avineri and Steven 2013) or the spread of pop-up infrastructure in Germany (Jennings et al. 2021; Kraus and Koch 2021) or the spread of the 15 min city model in Paris (Pozoukidou and Chatziyiannaki 2021).

These actions should be encouraged in order to encourage sustainable mobility and decarbonization and thus enable the development of more livable, sustainable and accessible cities. Micro-mobility is among the modal choices that should be encouraged by promoting not only the purchase but also the use and diffusion of sharing services. The correct use of e-scooters is the ideal mode of transport, useful and functional for daily travel, especially to cover the 'last mile' in central areas (Hosseinzadeh et al. 2021)

Thereby, the success of micro-mobility will be guaranteed by a greater diffusion of regulations. In fact, they have not been fully defined in many European states and several accidents have been recorded due to poor visibility or excessive speed that some noncompliant scooters can reach (Weinreich 2021;Tuncer et al. 2020). At the same time, it will be necessary to promote equity of use for all segments of the population and gender by promoting, for example, discounts or including in the fleet vehicles with seats and baskets for carrying shopping. At the basis of the improvement of these strategies there are studies to be carried out analyzing the demand for transport in terms of socio-demographic and travel habits (Nikiforiadis et al. 2021; Mitra and Hess 2021).

In this manuscript we have investigated the gender equity related to the use of micro mobility in an Italian regional context, statistically analyzing some data acquired through the administration of online surveys to users enrolled in micro mobility associations and therefore frequent users of this means of transport.

\section{Background on Micro Mobility Development in Europe}

Despite the fact that since 2019 there has been a gradual increase in the use and availability of e-scooters (electric scooters) in cities both in terms of rental, sharing and ownership (Campisi et al. 2020a, 2020b, 2021b), this development has been characterized by the lack of regulatory frameworks for the use and exploitation of emerging mobility modes. This has led to a pressing need for local and national regulations and approaches to organize the market and keep public spaces in order. Over the past 2 years, this has in turn led to widespread and often dissimilar changes in national regulations.

Specific regulations have been implemented across Europe, but without an allencompassing framework, with significant differences in the approach chosen between local and national levels, but also across countries. The European electric two-wheeler sharing market has experienced a significant increase, per vehicle, millions of units during the period 2017-2025 (European Commission n.d.). 
In particular, the European electric two-wheeler sharing market is estimated to reach 597.2 million by 2025. In Europe, Spain dominated the European electric two-wheeler sharing market in 2018, owing to the popularity of this form of transportation in major parts of the country. However, Germany is projected to be the largest European market in the coming years (European Institute for Gender Equality (EIGE) (n.d.-a)).

In addition to the spread of scooters/mopeds there has been an increase in kickscooters from the end of 2019.

Indeed, many kick scooters sharing service providers have entered the market, realizing the growth potential in the domain. Therefore, the kick scooter sharing service category is set to grow. Considering trip types, the European electric two-wheeler sharing market is categorized into one-way and round trips. The first category characterized the market in 2018 and is expected to continue to dominate it in the coming years, mainly due to the flexibility and convenience associated with his service.

About the vehicles, e-scooters are similar to traditional scooters, although they have a battery that powers an electric motor. These lightweight, electric, floating vehicles are often made available in urban areas through sharing schemes that allow users to locate, reserve, (un)lock and pay for their use through their smartphones. Electric two-wheeler sharing services are quite convenient for the general public, especially for daily commuters, as it helps them travel to their destination without having the need to own a vehicle. This also reduces the burden of additional expenses, such as maintenance, insurance, parking and charging. Users only have to pay on the basis of time and distance travelled together with an initial registration fee to use the service. Moreover, the mobile applications of the service providers offer all the details that are required and provide assistance at every step to ensure a higher level of convenience to the users.

Increasing technological progress in sharing services, growing concerns about greenhouse gas emissions, massive urban road congestion and increased convenience in using ride-sharing vehicles are the main drivers stimulating market growth.

Considering the progress in the part of legislation specific things took place individually in some countries. In September 2019, a new mobility law added e-scooters to the French highway code with measures including a minimum age (children as young as 8 years old) and guidelines on where they can be used. E-scooters are banned from sidewalks, their speed limit on roads is $20 \mathrm{~km} / \mathrm{h}$ and helmets are mandatory for children under 12. In Germany, a license for e-scooters for use on public roads is available if their maximum speed does not exceed $20 \mathrm{~km} / \mathrm{h}$ and if such vehicles are equipped with headlights and side reflectors, two independently functioning brakes and are also equipped with a bell or signal that can be used to warn other users of an approach (European Institute for Gender Equality (EIGE) (n.d.-b)).

Additionally, in early 2020, the Italian Ministry of Transport published new rules for e-scooters: in Italy they can be driven at a maximum speed of $25 \mathrm{~km} / \mathrm{h}$ on roadways where bicycles are allowed and $6 \mathrm{~km} / \mathrm{h}$ in pedestrian areas (European Institute for Gender Equality (EIGE) (n.d.-b)).

Further, recently, some cities such as Genoa have banned the use of scooters in urban areas because of repeated accidents. In Sweden, e-scooters must have brakes, an audible warning device, such as a bicycle bell, and riders under the age of 15 must wear a helmet. In Spain, the national traffic authority sets a speed limit of $25 \mathrm{~km} / \mathrm{h}$ for e-scooters and requires that they be insured (Nerén n.d.).

In the UK, the use of e-scooters is legal only on private land, and the government plans to review the regulation and governance of emerging transportation modes, including e-scooters, beginning with a consultation on e-scooter use (Weinreich 2021).

In addition to those mentioned in the previous section, other EU countries have proposed regulations or published guidelines for local authorities on the use of e-scooters. Across the pond, some United States (U.S.) cities have begun experimenting with geo fencing to enforce speed limits and limit the areas where e-scooters can operate. Despite the potential of this technique, such arrangements appear, at the European level, to lack 
regulation that respects privacy issues and establishes a Europe-wide framework for geo fencing (Oeschger et al. 2020). The use of micro mobility and in particular the e-scooter results as complementary to public transport and has recently undergone a greater rise characterized by a greater number of cities that have included on an experimental basis the use of such means and the growth of numerous service managers in different European contexts (Twisse 2021). Safety issues are one of the most pressing issues to be addressed, especially the needs and safety of other vulnerable road users. European and UK statistics underline the importance of placing limits on their speed and power, as well as banning their use on sidewalks where cycling is not allowed (Marzulli; Sokolowski 2020).

Other equally relevant strategies can help make e-scooters safer, ranging from design to regulation and operation.

In addition, special attention should be given to the planning and design of public space, which in turn has spillover effects on the safe use of micro-vehicles and the occupation of public space, and finally, further attention should be paid in the near future to the environmental impact aspect: although scooters may be zero-emission vehicles, initial studies seem to indicate that these vehicles are not as environmentally friendly as initially thought (Sharp 2019; Tuncer and Brown 2020; Madapur et al. 2020).

Their short lifespan (some studies indicate three months to a year), common charging and maintenance patterns, and the waste generated from the disposal of their parts do not seem to meet the highest standards of sustainability. Electric scooter operators need to address these concerns, not only to promote sustainable mobility, but also for the sustainability of their business models.

\subsection{The Spread of Micromoblity on Italy}

An increasing number of Italians have an interest in buying scooters. The physical and online stores propose offers and among the streets are more and more citizens who appreciate the convenience (Statistica 2021). Investigating the role of attitudes in the choice of an electric scooter via a hybrid choice model: an exploratory application to the city of Trieste, Italy. Investigating the role of attitudes in the choice of an electric scooter via a hybrid choice model: an exploratory application to the city of Trieste, Italy (International Transport Forum 2020; Statistica 2021).

After the lockdown with the widespread pandemic and the need to find green means of transport that allow social distancing, the electric scooter conquers the market and spreads more than expected. Some national surveys show that $34 \%$ of people living in urban areas confirm that they have changed their travel habits and modes to cope with social distancing due to restrictions (Scorrano and Danielis 2021). Even if the car is still the preferred mean of transport, more than one Italian out of two (56.7\%) uses it to go to the office (when he cannot do smart working) or for daily trips, and if public transport is still the second choice, used by two Italians out of five $(22.5 \%)$, alternative means of transport are growing and replacing the shared mobility that was strong in recent years. Before the lockdown, car sharing was very popular, at least in large urban areas. With the onset of sanitation issues, the idea of sharing a small space with strangers has become a topic to be discarded. Shared mobility has, in fact, seen a big drop in usage. This is also true of car rental, used mainly by tourists.

On the other hand, micro-mobility has improved, that is, the set of travel systems that are used to cover short distances mostly in the city with less polluting means than traditional means such as: scooters, skateboards, electric scooters, bicycles and pedal assisted bicycles. Among all these systems, the electric scooter stands out, making a giant leap from 4900 units sold in December 2019 to 27,150 in December of the following year. Bike sharing, a good $15 \%$ of which is all-electric, is also among the micro-mobility services that have grown the most in the post-lockdown period.

After all, the market does nothing but adapt to citizens' demands. Restrictions and new circulation problems are not underestimated by the system of supply and demand. 
So much so that in 2020, in order to regulate the large number of scooter users, rules have been put in place to determine their correct use.

\subsection{Gender Gap on Sustainable Mobility Choices}

The perspective given to sustainable urban mobility is based on an increased emphasis on environmental sustainability and digitization through the deployment of digital platforms related to Mobility as a Service (MaaS) (Shaheen and Cohen 2020).

In addition, a third goal is emerging, namely the gender perspective.

Gender equality for women and girls is included in the fifth sustainable development goal (SDG 5) which calls for promoting and strengthening gender u-equality and women's empowerment across the board in all sectors, including urban mobility. This implies a greater need for analysis of behavior patterns, assessment of travel habits but also a greater focus on the projection of mobility systems that are suitable for them. Modal choices are a function of gender (Hanson 2010).In fact, some studies have shown that men's trips and motivations are simpler than those of women, who often have to accompany their children or relatives, and are characterized by a combined use of different modes of transport (e.g., walking and bus) at different times of the day. Figure 1 shows the distribution of European modal choices according to gender (European Commission n.d.).
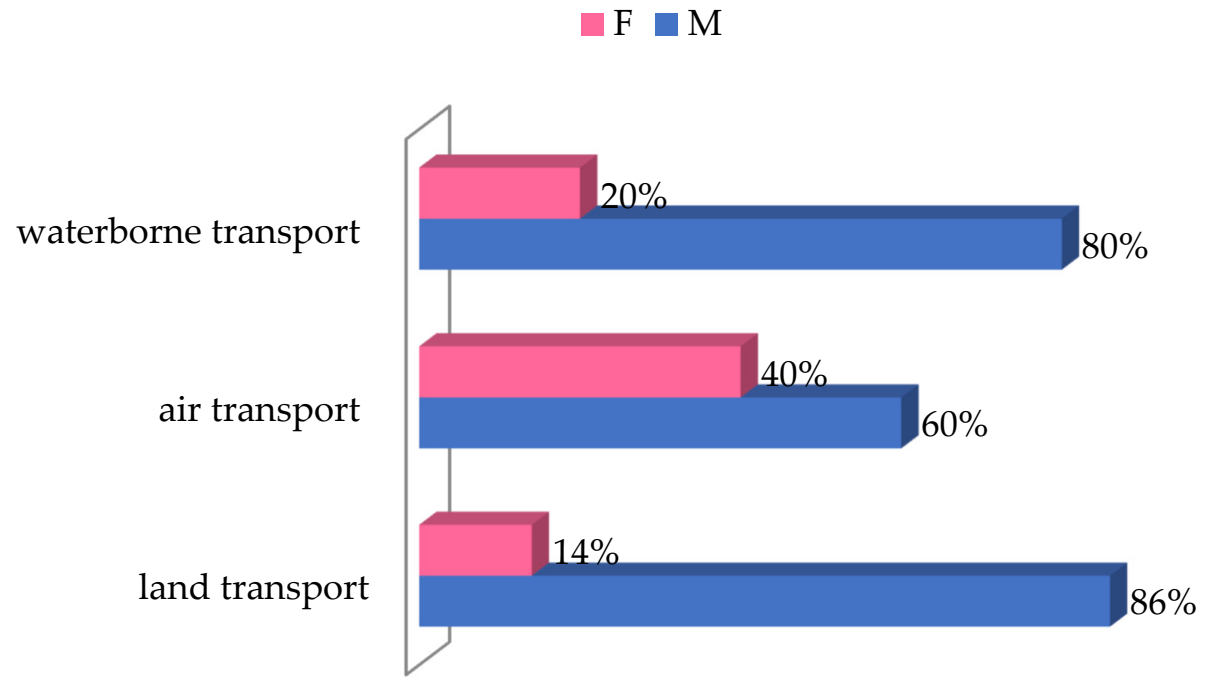

Figure 1. Gender gap trend in Europe (data source: European Commission (n.d.) https://ec.europ a.eu/transport/themes/social/women-transport-eu-platform-change_en, accessed on 10 August 2021).

This is due to the fact that, on average, women stay home more than men and when they do move, they make shorter trips.

A conceptual model incorporating the impact of gender equity and human development on women's representation in the legislature and public health spending, and their combined impact with the human environment (population density, aging population and urban population) was conducted to explore the context of COVID-19 (Leung et al. 2020).

Researchers have recently conducted a strategic analysis of urban mobility from the perspective of sustainability and gender equity in the context of the pandemic, identifying a number of effective strategies to address the post-COVID-19 urban mobility scenario through a SWOT analysis (González-Sánchez et al. 2021). Some research confirms that women use new sustainable and smart transportation modes-such as micro mobility sharing platforms-more often than men, as they provide a level of flexibility that is not offered by traditional transportation methods, such as public transportation or private vehicles (Nerén n.d.).

However, even though women require more flexible means of transportation, due to the historical division of roles by gender socially, occupationally and economically, they 
continue to be the primary users of public transportation (European Institute for Gender Equality (EIGE) (n.d.-a), n.d.-b).

In general, when talking about disparity the following three (3) concepts should not be confused (Herrera 2007).

- Equal is defined as the same or exactly the same;

- $\quad$ Fair is defined as just or appropriate under the circumstances;

- $\quad$ Equity is defined as the quality of being just and impartial.

Gender equity/equality related to mobility is an issue with wide spatial spread but recent interest as shown in Table 1. Specifically, some bibliographical references related to the above-mentioned theme have been included, underlining the time span and geographical location.

Table 1. Geographical spread of gender equality related to mobility concept.

\begin{tabular}{ccc}
\hline Country & Period & Reference \\
\hline Commonwealth countries & 2005 & (Morley 2005) \\
Columbia (Bogotà) & 2005 & (Lecompte and Pablo 2017). \\
Canada & 2009 & (Anderson et al. 2009) \\
(Milan and Creutzig 2017). \\
Columbia (Medellin) & $2009-2012$ & (Mishra et al. 2014) \\
India (Uttar Predesh) & 2014 & (Umaña-Barrios and Gil 2017). \\
North America (Costa Rica) & 2017 & (Sagaris and Tiznado-Aitken 2018). \\
Chile (Santiago) & 2018 & (Habitat 2018). \\
Africa (Nairobi) & 2018 & (Bastian and Börjesson 2018). \\
Swedish (Stockholm) & 2018 & (Vecchio et al. 2020) \\
Latin America (Curitiba, & 2020 & (Kronsell et al. 2016) \\
Medellin and Bogotá) & 2020 & (Al-Rashid et al. 2020) \\
Sweden & 2020 &
\end{tabular}

Safety, accessibility and reliability of transport are among the variables analyzed by the European TinnGO project on gender equity in mobility. Future research on the data collected through the survey would help operators successfully improve their mobility offerings for women (Pirra et al. 2021).Until that time, already published research work focuses on the definition of "fairness" in transport especially for women using public transport, future autonomous cabs or bike sharing. This concept is related to equality of opportunity, equity and justice (including procedural, social and distributive justice) (Hail and McQuaid 2021). Factors such as safety, cost, physical design of infrastructure and vehicles, and factors such as low income or childcare responsibilities emerge as deterrents to the use of certain modal choices by women (Uteng 2012). Other research focuses on the concept of equality and highlights the critical issues that often lead to different perceptions of in-flight safety or gender equality considering both passenger and driver perspectives (Campisi et al. 2021c).

Lack of safety in transportation is an issue that affects all modes of transportation equally and where perceptions of public transportation differ significantly between men and women for different transport modes (Ouali et al. 2020). A significant number of women around the world do not feel safe on public transportation and have been victims of some type of verbal or physical harassment in public spaces (Orozco-Fontalvo et al. 2019).

Gender equity is an important goal to achieve in every area of society, including mobility. It is now widely accepted that mobility (and thus micro-mobility) is not genderneutral and that the choices of authorities and companies have an impact on women's travel patterns. For both bicycles and e-scooters, the majority of users are male (Laa and Leth 2020). There are two main factors the first being cultural and the second related to safety.

Most women's tasks involve household chores, such as picking up children from school, shopping for groceries, tasks that are more difficult to perform on a light two- 
wheeled vehicle. In addition, appearance is one of the factors that often discourages the use of some forms of mobility (this implies, for example, arriving impeccably groomed and dressed, which is not always easy when using shared bikes and scooters-think about helmets, speed and weather conditions) (Laa and Leth 2020). The majority of the female population tends to travel on foot or by public transport, much more than men do. In France, two-thirds of the users of public transport services are women. Women generally do most of the unpaid care work, a percentage that varies by country: in Italy it is $63.5 \%$ (Statistica 2021). This forces them to travel different, much more complex patterns of roads that, in most cases, are not directed towards the city center, an area that is usually better organized and more easily accessible. So, if men usually, on a weekday, make the journey from home to work and vice versa, women follow what is called trip-chaining: a mode of travel consisting of several concatenated stages. In most cases, however, the means of transport are not designed for this type of travel, which often requires stops in areas of the city that are poorly connected or where public transport runs infrequently. The disadvantage faced by women is mainly due to a lack of gender data, in this case a lack of perspective (Cinti; Curreli).

The second important factor is safety, not only related to the reduction of aggression and violence. As a result, a lot of women are forced to face fear while they use public transport (Hail and McQuaid 2021). This fact certainly induces women to change their behavior and habits, some even going so far as to give up work so as not to have to be exposed to that feeling during the journey. From admiration whistles, to lewd looks, from sexual insults to boarding attempts. None of these behaviors have actual criminal value, but they all contribute to a constant feeling of threat. The invisibility of threatening gestures directed at the female population in public spaces is compounded by the fact that harassers act when women are alone; in fact, male chaperones, if any, are much less likely to be involved when they are. The lack of data is caused not only by the lack of reporting, but also by the fact that these behaviors are only in very few cases included in crime statistics. Safety therefore is related to the choice of safer means and therefore related to the search for better cycling infrastructure.

Separate bike lanes, shared roads and greater respect for rules will overcome the safety hurdle for women. Private companies in the mobility industry, concerned about the gender gap, should launch investment programs in bicycle infrastructure.

Safety is not only about the infrastructure but also about the vehicle. Electrified vehicles allow you to minimize the speed gap with other vehicles, and thus improve the feeling of safety. E-scooters are quite restrictive because of their small wheels and difficult handling, which is perhaps why we see the emergence of new form factors such as e-motors or light e-motors equipped with larger wheels.

The main change to expect is for all stakeholders in shared micro mobility to become aware of this gender gap and understand the need and potential for persuading women to adopt new shareable alternatives. Hiring women to use their creativity and innovation to design products for women is one way to change the male-dominated mobility industry. The private sector must become aware of its social justice impact to initiate sustainable change and close the gender gap.

The gender gap would also be explained by the ownership history of certain vehicles. Historically, two-wheeled motor vehicles were largely owned by men. This trend can be seen today, for example in Switzerland, where only $20 \%$ of moped owners are women. For this type of vehicle, we can add that they are designed more for men, especially in terms of the vehicle's weight-to-strength ratio. In general, we observe that men assimilate new technologies more quickly to integrate them into their habits. Women prefer to choose services provided by companies that have been in the market for more years than those that are emerging (Sallah and Caesar 2020). 


\section{Methodology}

The present study is focused on the identification of those factors that significantly affect gender equality for female micromobility users. Specifically, the online survey was carried out with 1000 female participants who are living in the metropolitan areas of Catania and Palermo, Sicily. About 139,000 women of age live in Catania and about 291,500 women of age live in Palermo (Statistica 2021).The sample analyzed consists of 1000 questionnaires.

Being a recent form of mobility and not yet widespread throughout the territory investigated, the sample is a good portion of the population living in the Sicily region. Data acquisition took place between June and December 2020 immediately after the lockdown. The period of data acquisition close to the lockdown certainly affected the number of survey participants while at the same time reducing many of the daily trips for fear of contagion. The questionnaires were administered online through the main social channels such as Facebook using pages dedicated to the mobility of the two cities analyzed so as to acquire a fair sample. The sample was selected from users of legal age with at least the possession of a diploma.

Figure 2 presents the general methodological framework of the present research.

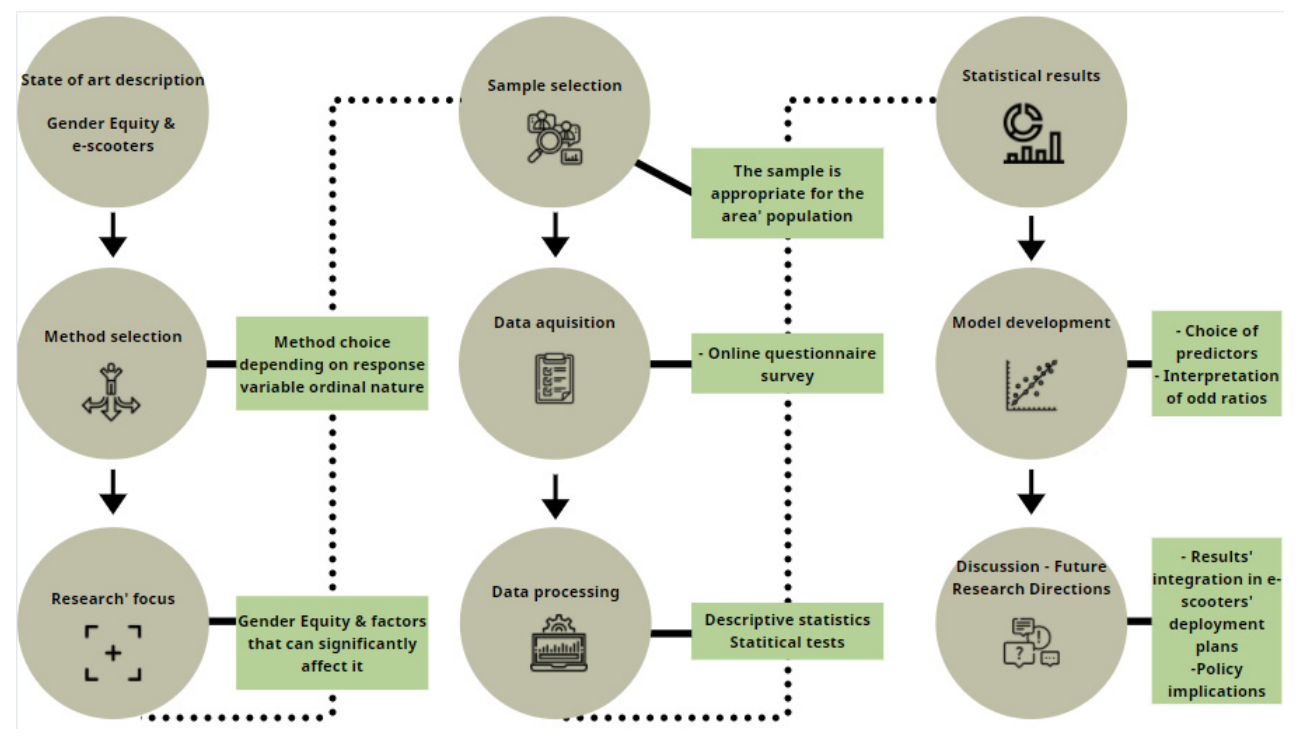

Figure 2. Methodological framework of the present research.

After the definition of the state of the art, the research was focused to the use of the appropriate model as well as the statistical analysis of the available data. Then, the interpretation of the model is crucial for the obtainment. At this point it should be mentioned that the current sample is concerned as representative. Specifically, the appropriateness of the sample is confirmed for a margin of error of $3.2 \%$ at a significance level of $a=5 \%$. The following estimation formula referred by (Daniel and Cross 1999; De Ceunynck et al. 2021; Naing et al. 2006) is used for the sample estimation.

$$
n=\frac{N * z^{2} * p *(1-p)}{\varepsilon^{2} *(N-1)+z^{2} * p *(1-p)}
$$

where:

$n$ : the sample size

$N$ : the population size of the Palermo and Catania Provinces

$z$ : the z-statistic for a level of confidence

$p$ : the expected population proportion

$\varepsilon$ : the margin of error 
For the conduct of the present research the following values were used:

$N=2,281,056$ (City Population)

$z=1.96($ since $\mathrm{a}=5 \%)$

$p=0.5$

$\varepsilon=0.032$

Therefore, the equation is finds the following form:

$$
n=\frac{2281056 * 1.96^{2} * 0.5 *(1-0.5)}{0.0566^{2} *(2281056-1)+1.96^{2} * 0.5 *(1-0.5)}=300
$$

It should be noted that the selected sample (937 interviewees) is concerned as appropriate for the present study.

The present research is divided into three (3) sections. Specifically, the first section concerns the sociodemographic characteristics of the participants (age, educational level, occupation). The second section discusses participants' main reasons for choosing micromobility modes and sharing-mobility.

Additionally, the frequency of use (micromobility, sharing mobility), the ownership status of micromobility modes as well as the main problems that hold women back from using micromobility modes are included as well. The last section concern women's perceived safety feeling by using micromobility and sharing mobility modes. Last, this section includes the perceived gender equality feeling by using micromobility (as passengers) and sharing mobility modes (as drivers).

The first step of the research is the production of the descriptive statistics and correlation analysis for the examination of the data structure. Concerning the correlation analysis, it should be mentioned that Pearson correlation was used. After the realization of these basic statistical steps, authors applied the ordinal regression modeling in order to reveal the underlying factors that affect gender equality concerning micromobility. Ordinal regression is widely used in social sciences for the prediction of variables of ordinal nature.

\section{Results}

\subsection{Descriptive Statistics}

Descriptive statistics is the initial part of the analysis that has been performed, so as to achieve investigation of the structure of the, via online survey, collected data. The whole statistical analysis was conducted using the SPSS v27.0 version.

The total number of 1000 participants concern only female users.

The present research is based on the knowledge and evaluation of social and macroeconomic variables and the perception that the interviewed users have of the use of scooters. This perception may be influenced by previous experiences.

The majority of them were between 31 and 45 years old (52.5\%) while the second age-group important group refers to the range 18-30 (25.1\%).

Regarding the educational level of the sample, most of the participants have Diploma Level education (56.8\%) and $35.9 \%$ of them held degrees. In parallel, $42.3 \%$ of them assumed to be employees and almost $20 \%(19.5 \%)$ were students.

Table 2 below, presents the descriptive statistics of the variables that used in the model development. 
Table 2. Descriptive statistics.

\begin{tabular}{|c|c|c|c|c|}
\hline Code & Description & Measure & Values & Frequency $(\%)$ \\
\hline \multirow{4}{*}{ Age } & \multirow{4}{*}{ Age of participant } & \multirow{4}{*}{ Ordinal } & $0: 18-30$ & 25.1 \\
\hline & & & 1: $31-45$ & 52.2 \\
\hline & & & 2: 46-65 & 18.1 \\
\hline & & & 3: $>65$ & 4.6 \\
\hline \multirow{3}{*}{ Educational_Level } & \multirow{3}{*}{ Educational Level of participant } & \multirow{3}{*}{ Ordinal } & 0: Diploma & 56.8 \\
\hline & & & 1: Degree & 35.9 \\
\hline & & & 2: $\mathrm{PhD}$ & 7.3 \\
\hline \multirow{5}{*}{ Job_Occupation } & \multirow{5}{*}{ Job or occupation of participant } & \multirow{5}{*}{ Nominal } & 0 : Student & 19.5 \\
\hline & & & 1: Freelancer & 14.8 \\
\hline & & & 2: Employee & 42.3 \\
\hline & & & 3: Retired & 5.7 \\
\hline & & & 4: Unemployed & 17.7 \\
\hline \multirow{5}{*}{ Reason_Sharing_Mobility } & \multirow{5}{*}{$\begin{array}{l}\text { Main reason for moving by sharing mobility } \\
\text { vehicles }\end{array}$} & \multirow{5}{*}{ Nominal } & 0: Work & 3.4 \\
\hline & & & 1: Accompanying children to school & 2.3 \\
\hline & & & $\begin{array}{l}\text { 2: Accompanying someone to shopping or processing } \\
\text { paperwork }\end{array}$ & 3.7 \\
\hline & & & 3: Leisure & 30.5 \\
\hline & & & 4: Other & 60.1 \\
\hline \multirow{5}{*}{ Frequency_Sharing_Mobility } & \multirow{5}{*}{$\begin{array}{l}\text { How often do the participant move by } \\
\text { sharing mobility vehicles }\end{array}$} & \multirow{5}{*}{ Ordinal } & 0 : Once or several times/day & 0.0 \\
\hline & & & 1: Once or several times/week & 1.4 \\
\hline & & & 2: Once or several times/month & 7.7 \\
\hline & & & 3: Never & 88.9 \\
\hline & & & 4: I don't know & 2.0 \\
\hline
\end{tabular}


Table 2. Cont.

\begin{tabular}{|c|c|c|c|c|}
\hline Code & Description & Measure & Values & Frequency $(\%)$ \\
\hline \multirow{6}{*}{ Problem_Micromobility } & \multirow{6}{*}{$\begin{array}{l}\text { The main problem that holds participants } \\
\text { back from using micromobility vehicles }\end{array}$} & \multirow{6}{*}{ Nominal } & 1: Problems related to the transport of children & 5.1 \\
\hline & & & 2: Problems related to the transport of shopping or bags & 25.1 \\
\hline & & & 4: Problems related to makeup removal & 0.0 \\
\hline & & & 5: Possible collisions with pedestrians and car/bike & 27.6 \\
\hline & & & 6: Possible violence action & 19.6 \\
\hline & & & 7: Health and/or posture problems & 16.3 \\
\hline \multirow{2}{*}{ Ownership_Micromobility } & \multirow{2}{*}{ Participant owns micromobility vehicle } & \multirow{2}{*}{ Nominal } & 0: No & 95.8 \\
\hline & & & 1: Yes & 4.2 \\
\hline \multirow{4}{*}{ Safety_Micromobility } & \multirow{4}{*}{$\begin{array}{l}\text { Perception of safety feeling linked to the } \\
\text { micromobility vehicles' use }\end{array}$} & \multirow{4}{*}{ Ordinal } & 1: Strongly Disagree & 30.8 \\
\hline & & & 2: Disagree & 47.9 \\
\hline & & & 3: Uncertain & 19.8 \\
\hline & & & 4: Agree & 1.5 \\
\hline \multirow{5}{*}{ Safety_Sharing_Mobility } & \multirow{5}{*}{$\begin{array}{l}\text { Perception of safety feeling linked to the } \\
\text { sharing mobility vehicles' use }\end{array}$} & \multirow{5}{*}{ Ordinal } & 1: Strongly Disagree & 29.1 \\
\hline & & & 2: Disagree & 40.4 \\
\hline & & & 3: Uncertain & 23.3 \\
\hline & & & 4: Agree & 7.2 \\
\hline & & & 5: Strongly Agree & 0.0 \\
\hline \multirow{5}{*}{$\begin{array}{c}\text { Gender_Equality_Passenger_ } \\
\text { Micromobility }\end{array}$} & \multirow{5}{*}{$\begin{array}{l}\text { Perception of gender equality feeling linked } \\
\text { to the micromobility vehicles' use }\end{array}$} & \multirow{5}{*}{ Ordinal } & 1: Strongly Disagree & 43.0 \\
\hline & & & 2: Disagree & 45.8 \\
\hline & & & 3: Uncertain & 11.2 \\
\hline & & & 4: Agree & 0.0 \\
\hline & & & 5: Strongly Agree & 0.0 \\
\hline
\end{tabular}


Table 2. Cont.

Code Description

Gender_Equality_Driver Sharing_Mobility

Perception of gender equality feeling linked to the sharing mobility vehicles' use
Measure

Values

1: Strongly Disagree

2: Disagree

Ordinal
4: Agree

5: Strongly Agree
Frequency (\%)

2.7

5.1 
Consequently, all participants were asked reveal aspects of their travel habits while using micromobility or sharing-mobility vehicles. Starting by the reason of using sharing mobility infrastructure, participants stated by $60.1 \%$ other reasons than leisure $(30.5 \%)$, Work (3.4\%) or accompanying other people or children (6.0\%). However, questions according to the use frequency, revealed that $88.9 \%$, never use sharing mobility vehicles while only $7.7 \%$ use them once or several times per each month. Furthermore, the majority of participants stated that they do not feel safe $(40.4 \%, 29.1 \%)$ during their trips and they presented to be significant uncertain $(90.5 \%)$ about the gender equality feeling by sharing mobility vehicles' use.

On the other hand, concerning the micromobility vehicles, it should be highlighted that $95.8 \%$ of participants were not owners of such a vehicle and with respect to the main problems that holds them back from generally using them, was the possible collisions with pedestrians and car or bike by $27.6 \%$, problems related to the transport of shopping or bags by $25.1 \%$ and possible violence action by $19.6 \%$. Further, $47.9 \%$ and $30.8 \%$ of the participants responded that they disagree and strongly disagree, respectively, that micromobility vehicles produce a feeling of safety. In a similar manner, $45.8 \%$ and $43 \%$ of the participants disagree and strongly disagree, respectively, that using micromobility vehicles does not giving the feeling of gender equality.

Our research results confirm that the scooter sharing services were more often used for recreation (McKenzie 2019; He et al. 2019; Hardt and Bogenberger 2019). The ownership percentage is actually low, but this fact doesn't mean that residents of the study area do not use e-scooters. Specifically, the spread of shared micro-mobility is growing in Sicily due to the increasing demand for shared services for daily travel and for tourism purposes. Since June 2020, four companies that deal with the service of shared micro-mobility have placed over 1600 scooters in Palermo and since July 2021 about 17 operators in the sector have participated in the call of the Municipality of Catania for the deployment of about 1000 scooters, just a few months after the diffusion of the bike rental service. These widespread services can bring the two cities in the same way as other European cities under the banner of sustainable mobility. An important flaw today is the partial presence of bike paths and protected routes in both Sicilian cities.

In the USA, James et al. conducted a survey in Rosslyn, Virginia as well as research on differences in perceived comfort and safety between those who have used dockless e-scooters before and those who have not, the present work found that more than three quarters of the sample had a perception of feeling "unsafe" or "very unsafe (James et al. 2019). In contrast, opposite results were achieved in Saudi Arabia according to the study conducted by (Almannaa et al. 2021).

From the perspective of gender equity related to both micromobility and shared mobility, the results confirm what has been described by (Campisi et al. 2021a).

The results confirm the presence of gender heterogeneity in e-scooter use consistent with previous studies (McKenzie 2019; Jiao and Bai 2020; Zagorskas and Burinskiene 2020). This plays an important role in preferences related to e-scooter use. Several factors, including safety, comfort, and social expectations, often make this choice less convenient for urban transportation for women than men in agreement with (Campisi et al. 2020a).

\subsection{Correlation Matrix}

Another preliminary task that had to be done before developing statistical models is the estimation of a Pearson correlation matrix, in order to reveal potential correlations between the variables. The estimation reveals that a significant relationship existed between the job or occupation of the participant, the main reason for using sharing mobility vehicles $(\mathrm{r}=-0.212, p=0.01)$ and the frequency $(\mathrm{r}=091, p=0.01)$, while also one between the occupation and the ownership of micromobility vehicles $(\mathrm{r}=-0.13, p=0.01)$. Further, correlation matrix indicated a statistically significant relationship between the reason and the frequency of using sharing mobility infrastructure $(\mathrm{r}=-0.057, p=0.01)$. Additionally, the reason of a sharing mobility vehicle trip, effects on feeling of safety according to the 
results $(r=-0.074, p=0.05)$. Finally, the estimation revealed significant correlations for the gender-equality feeling in sharing mobility only. Specifically, the educational level seems to have a higher impact $(\mathrm{r}=0.76, p=0.05)$.

Even though the determined Pearson correlation values had statistical significance, they were far below the recommended value of 0.7 suggesting that the determined significant correlations were not statistically significant (Yatskiv and Spiridovska 2013).

Table 3 presents the correlation coefficients among the variables.

\subsection{Gender Equality Estimation by Ordinal Regression Modeling}

The present section concerns the development of the regression model. Due to the ordinal nature of the dependent variable the ordinal regression modeling was selected. The micromobility passenger gender equality as perceived by the female participants is the dependent variable. At this point it should be highlighted that all independent variables (predictors) were concerned as equal to be included in the proposed model. Therefore, many "try and error" tests were performed before the final selection of the predictors. As it is widely known ordinal regression models' interpretation is based on the estimated odd ratios. Therefore, the selection of the predictors should result in a model with meaningful odd ratios which can give enlightening results concerning gender equality for micromobility modes.

Ordinal regression is concerned as one of the three (3) types of logistic regression. Ordinal regression models estimate the odds of an event, and all the events that are ordered before it, to occur instead of not occurring. Thus, the odds are indicated as:

$$
\theta j=\operatorname{prob}(\text { score } \leq \mathbf{j}) /(1-\operatorname{prob}(\text { score } \leq \mathrm{j}))
$$

The following equation indicates the general mathematical expression of an applied ordinal regression model:

$$
\ln (\theta j)=\alpha j-\beta X
$$

where $\mathrm{j}$ is numbered from 1 to the number of the dependent variable categories (Mukaka 2012). Coefficients' minus signs express that larger coefficients are related with larger scores.

After concerning the results of the descriptive and inferential statistical analysis the ordinal regression model was developed in order to reveal the factors that mostly affect gender equality for micromobility modes.

Tables 4 and 5 include the estimation of the model's parameters and the overall model's fitting indices as well. Model fitting information indicate a statistically significant reduction ( $\operatorname{sig} \leq 0.05)$ of the $-2 \log$-likelihood $(-2 \mathrm{LL})$ when the independent variables (predictors) are integrated into the model. This fact implicates that the introduction of the selected predictors can lead to a significant improvement of the model compared to the baseline model that contains no predictors (Intercept only). 
Table 3. Correlation matrix.

\begin{tabular}{|c|c|c|c|c|c|c|c|c|c|c|c|c|}
\hline & & 1 & 2 & 3 & 4 & 5 & 6 & 7 & 8 & 9 & 10 & 11 \\
\hline 1 & Age & 1 & & & & & & & & & & \\
\hline 2 & Educational_Level & $-0.102 * *$ & 1 & & & & & & & & & \\
\hline 4 & Reason_Sharing_Mobility & -0.027 & 0.029 & $-0.212 * *$ & 1 & & & & & & & \\
\hline 5 & Frequency_Sharing_Mobility & 0.030 & $0.066^{*}$ & $0.091^{* *}$ & -0.057 & 1 & & & & & & \\
\hline 6 & Problem_Micromobility & -0.016 & -0.035 & -0.039 & -0.019 & -0.001 & 1 & & & & & \\
\hline 7 & Ownership_Micromobility & -0.057 & 0.022 & $-0.130 * *$ & 0.039 & -0.045 & -0.016 & 1 & & & & \\
\hline 8 & Safety_Micromobility & 0.012 & -0.042 & 0.004 & -0.059 & 0.036 & $-0.066^{*}$ & -0.044 & 1 & & & \\
\hline 9 & Safety_Sharing_Mobility & -0.010 & 0.028 & -0.037 & -0.074 * & 0.033 & -0.016 & 0.002 & 0.021 & 1 & & \\
\hline 10 & Gender_Equality_Passenger_Micromobility & -0.031 & 0.011 & -0.035 & 0.044 & -0.004 & 0.004 & 0.033 & 0.001 & -0.003 & 1 & \\
\hline 11 & Gender_Equality_Driver_Sharing_Mobility & -0.015 & $0.076^{*}$ & 0.002 & 0.058 & -0.032 & -0.061 & 0.018 & -0.043 & 0.024 & $0.068^{*}$ & 1 \\
\hline
\end{tabular}

${ }^{* *}$ Correlation is significant at the 0.01 level (two-tailed); ${ }^{*}$ Correlation is significant at the 0.05 level (two-tailed). 
Table 4. Parameter estimates for the Gender Equality model.

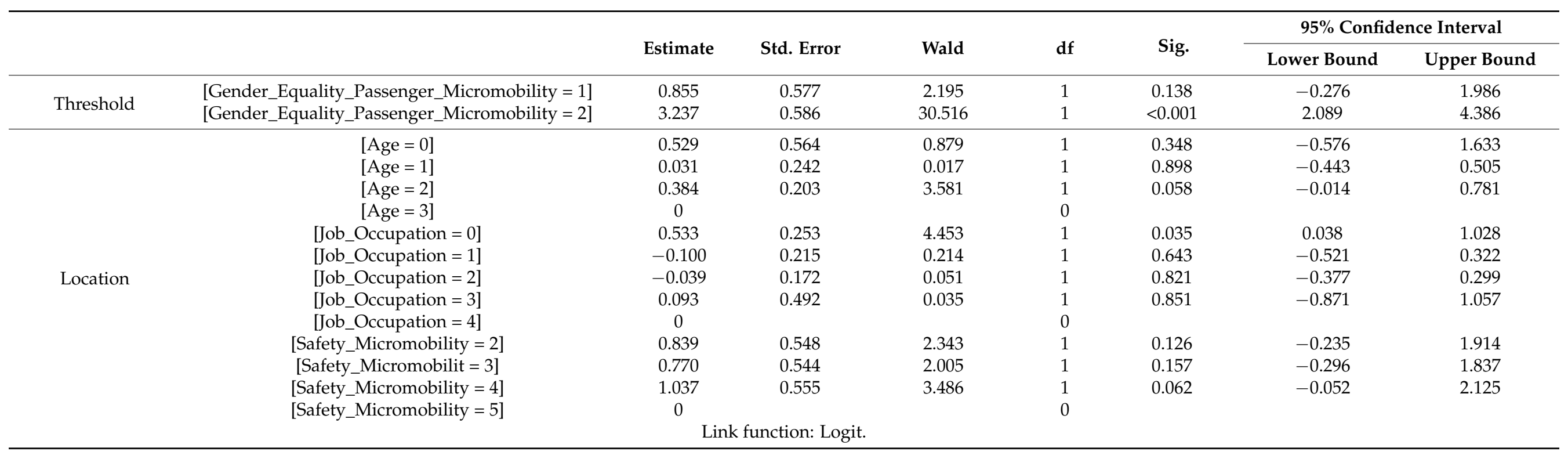


Table 5. Overall fitting indices for the Gender Equality model.

\begin{tabular}{|c|c|c|c|c|c|}
\hline \multicolumn{6}{|c|}{ Model Fitting Information } \\
\hline & $\begin{array}{c}-2 \log \\
\text { Likelihood }\end{array}$ & Chi-Square & $\mathrm{df}$ & & Sig. \\
\hline Intercept Only & 297.242 & & & & \\
\hline Final & 279.196 & 18.046 & 10 & & 0.050 \\
\hline \multicolumn{6}{|c|}{ Goodness-of-Fit } \\
\hline & Chi-Square & $\mathrm{df}$ & & Sig. & \\
\hline Pearson & 95.342 & 92 & & 0.385 & \\
\hline Deviance & 84.460 & 92 & & 0.699 & \\
\hline \multicolumn{6}{|c|}{ Pseudo R-Square } \\
\hline Cox and Snell & & & 0.018 & & \\
\hline Nagelkerke & & & 0.021 & & \\
\hline McFadden & & & 0.009 & & \\
\hline
\end{tabular}

Further, the Goodness-of-Fit tests reveal that the model is consistent to the data ( $\mathrm{p}$ values $>0.05$ ) since the null hypothesis (Ho) indicates that the model fit is good. Regarding the explained variance of the dependent variable the Nagelkerte R-square suggests that the selected model can explain $2.1 \%$ of the dependent' variable variance. High p-values $(>0.05)$ in the goodness-of-Fit indicate that the proposed model is consistent to the data since the null hypothesis (Ho) indicates that the model fit is good. $\mathrm{R}^{2}$ indicates the total variance of the dependent variable that can be explained by the selected predictors. This can be explained if the model is enough robust to satisfy the goodness-of-Fit index but still has low $\mathrm{R}^{2}$. Additionally, the existence of statistically significant variables may imply some unobserved heterogeneity in the data that holds low goodness-of-fit metrics. Last, the $\mathrm{R}^{2}$ metric is quite general, and it is mainly used for comparative purposes only.

Additionally, regarding the indepented variables, an extra modification has to be made. Specifically, in order to define as a reference category the one that has a higher number of participants instead of the last one (SPSS default setting), the variable Age was recoded with its classes' sequence to be reverted. The main reason is that the last class of the independent variable (referenec category) should collect a reasonable number of responses.

Last, the prediction power of the proposed model is assessed. Table 6 presents the predicted and the actual values of the dependent variable as well. The sum of the table main diagonal elements expresses the correct predictions. The estimated accuracy occurs by dividing the number of the correct predictions by the total ammount of predictions which is equal to the survey' sample (1000). Finally, the accuracy of the proposed model is approximately $47.2 \%$.

Table 6. Classification between observed and predicted cases of the Gender Equality model.

\begin{tabular}{ccccc}
\hline \multirow{2}{*}{ Predicted } & \multicolumn{4}{c}{ Observed } \\
\cline { 2 - 5 } & Strongly Disagree & Disagree & Uncertain & Total \\
\hline $\begin{array}{c}\text { Strongly } \\
\text { Disagree }\end{array}$ & 152 & 138 & 21 & 311 \\
\hline Disagree & 278 & 320 & 91 & 689 \\
\hline Total & 430 & 458 & 112 & 1000 \\
\hline
\end{tabular}

\section{Interpretation}

The present section focuses on the interpretation of the developed model. As it has been already mentioned the interpretation of the ordinal regression models is based on the estimation of the odd ratios. The estimation of the odd ratios is realized among the 
statistically significant intervals of the predictors (response variables) and their reference categories. The intervals that marginally overcome the research confidence level were included as well. Table 7 presents the estimated odd ratios for the gender equality model.

Table 7. Odds ratio results for the Gender Equality model.

\begin{tabular}{ccc}
\hline Variables & Intervals & Odds Ratios \\
\hline Age & $\begin{array}{c}31-45 \\
\text { (Reference category) }\end{array}$ & 1.467 \\
Job_Occupation & Retired & 1.704 \\
Safety_Micromobility & Unemployed (Reference \\
& category) & Uncertain \\
\hline
\end{tabular}

Useful conclusions can be drawn based on Table 7. For instance, people of age 3145 group, found to be approximately 1.5 times more likely to feel a narrower gender gap in micromobility than the group of age 18-30. In a similar manner, retired people were found to also feel more gender-equal 1.7 times more than the unemployed. Eventually, those who were uncertain about the provided safety of micromobility vehicles, were found almost three times more likely to perceive a bigger gender gap compared to the respondents who agree about the existence of gender equality.

The interpretation of ordinal regression models is based only to the interpretation of the estimated odd ratios. Many published papers (Campisi et al. 2021c; Georgiou et al. 2021; Nikiforiadis and Basbas 2019) that used the same methodology interpret the odd ratios only in the interpretation session.

\section{Discussion}

Firstly, it is very important to mention that the added value of the present research is the identification of the factors that affect women' gender-equality perception. Specifically, it was found that the age, the job occupation as well as the perceived safety level of the respondents are crucial towards the gender-equality level identification. At this point it should be mentioned that the proposed model should not be evaluated "strictly" about its prediction power and its metrics. The main purpose of ordinal regression model' development is the calculation and the interpretation of the odd ratios. Many similar researches that used the same methodology have been published until now (Beecham and Wood 2014; Grudgings et al. 2018).

Additionally, a very crucial part of the present research is the identification of the reasons that hold back women from choosing micromobility modes. Micromobility companies and authorities should pay close attention to that causes and try to give solutions. For example, difficulties on carrying shopping bags should be integrated in the design of future micromobility vehicles by companies. Moreover, it is lastly proved that women feel more secure when they travel in pairs or groups (Grudgings et al. 2018) and this could be an additional component in policy making procedure e.g., group tickets might attract more women. Addressing the needs of women users would mean proposing a vision by and for women, addressing their concerns about safety in the use of these vehicles, offering them content on the communication channels preferred by women.

Additionally, literature reveals that men and women do not incept the concept of built environment' safety in a common degree (Heesch et al. 2012). Thus, traffic safety levels should be increased in the region in order more women to use micromobility vehicles. Violence actions should be investigated by local police authorities and a comprehensive plan that fosters personal security should be conducted as well. Eventually, comfort cannot be omitted, since female users tend to require higher comfort levels on their vehicles even in micromobility modes. Manufacturers should respect various needs that will increase 
comfort and the construction cost (saddle quality, suspension range etc.) but in a long-term, it might also attract more female users (Heesch et al. 2012).

One important aspect of the present research is the high percentage of women $(88.9 \%)$ that did not use e-scooters. The present research aims at investigating the factors that significantly affect gender equity in using e-scooters. Thus, it is very important to consider the women that find difficulties in using e-scooters and the reasons that lie behind it. Additionally, the present research highlights the reasons that hold women back from using e-scooters. For that main reason it is even more important to consider the percentage of women $(88.9 \%)$ that never used e-scooters. This women group can contribute significantly towards the identification of the deterring factors regarding e-scooters use.

It is also very important to mention that the women who participated in the present research did not agree $(0 \%)$ or strongly agree $(0 \%)$ with gender equality in micromobility. This fact should be taken into consideration by local authorities and micromobility operators in order to change this perception. It is undeniable that micromobility is one of the most dominant transport modes in urban areas with high potential of reducing emissions and therefore enhance a sustainable way of traveling (Heesch et al. 2012). Thus, it is obvious that cities should invest in this transport mode by offering equal gender opportunities to micromobility users.

Additionally, private micromobility companies aim at bridging the gender gap by promoting and hiring female leaders, launching of reverse mentorship programs, and joining in organizations that promote diversity, inclusion as well as gender parity (Twisse 2021). The integration of a gender perspective in the planning stage will not only bridge the gender gap in transport and specifically in micromobility but can also help women to adopt more environmentally friendly mobility patterns.

It is very important to mention that the enact of relevant policies can contribute towards the bridging of the gender gap. Specifically, focus should be given to the enhancement of gender mobility data as well as to the development of gender-tailored mobility services. Then, as it was previously mentioned, it is very important to promote gendersensitive planning at all stages such as the design, the implementation as well as monitoring and evaluation. Gender sensitive planning can integrate the different needs of women and men in all of its stages. At this point it should be mentioned that many European cities took many initiatives towards the promotion of gender sensitive planning. United Kingdom (UK) is conducting gender auditing and national transport surveys with main focus on women' needs since 2000 (Nerén n.d.). Germany (Berlin) aims at providing equal gender travel opportunities across the city with the enhancement of the accessibility and safety levels of public transport (Cinti). The city of Bolzano in Italy is offering to women dedicated transport services (Pink Taxi, dedicated parking areas) in order to increase women's flexibility and meeting their needs (Färber 2011). In the city of Vienna (Austria), promotion is given to active ways of transportation and public transport by re-allocating street space and by enhancing user-friendliness in public transport (Curreli). In Sweden, the city of Malmo promotes gender-balanced areas with the active participation of women in the planning process (Damyanovic et al. 2013).

Of course, more actions and synergies are required towards the bridging of the gap, especially when e-scooters are concerned. It would be very useful for private micromobility companies as well as for competent authorities (e.g., municipalities, ministries) to evaluate micromobility schemes in terms of gender equality. Additionally, micromobility companies in collaboration with local authorities can foster the adoption of micromobility modes by women by integrating gender sensitive measures. For example, the creation of dedicated parking facilities (e.g., with increased safety) for women as well as reduced fares during specific time periods may assist towards the adoption of micromobility modes by women. The assessment of these or similar initiatives can shed more light on how sensitive women are in these changes. Additionally, the creation of gender related databases can give a real-time overview of gender equality level in a broader scale. Furthermore, enrichment of the available data with spatial data could give another important perspective into this 
research topic. By defining where female users do feel safe and secure to use micromobility modes and where they do not, might assist the effort to analyze and understand where the aforesaid gender gap is wider. Besides, research have shown that the gap can be even five times smaller in the attractive urban areas that the least (United Nations n.d.).

The inclusion of the needs of micromobility users are the key for interpreting gender equality and trying to bridge the gender gap. Moreover, the organizing of raising awareness events (e.g., seminars, workshops, on-field activities) concerning gender equality should be assessed in future studies. Education of micromobility users as well as of the society in gender equality can prove vital towards the bridging of the gender gap.

Furthermore, it is necessary to consider that Italy had a period of total reduction in mobility from March to May 2020. A large part of the population could only move for medical purposes, work and to buy basic necessities. These modes of transport have been growing from May until September 2020, i.e., even after the lockdowns, because people have preferred not to use public transport and because these modes of transport allow to ensure social distancing and also thanks to government incentives for the purchase of electric mobility such as bicycles and scooters and also the approval of projects afferent to the cycling-pedestrian infrastructure. In addition, from June to July 2020 several shared micromobility companies have spread in Italy and in particular in Sicily, thus providing an additional transport service in the context examined.

It would also be necessary to increase efforts in infrastructure with safer bike lanes (wider, more adapted, separated from cars), penalties for dangerous behavior, to increase the feeling of safety. It would also be necessary to adapt the vehicles but also all the equipment derived from their morphology and needs. Concerning the present research's limitations it should be underlined that there is still a large information gap concerning women mobility needs. Especially, concerning micromobility, few researches have been conducted until now that reveal women real needs and how synergies between companies-authorities can help towards the meeting of these needs. Future research should be conducted towards this direction while the exchange of knowledge among researchers, companies and authorities can help in the creation of a more accessible, safe and gender sensitive environment in where users, despite of their gender, can travel safe and sustainable. Additionally, another limitation of the present research is that participants should have indicated how gender equality level can be increased. Therefore, more data would be available about the ways that can help towards the bridging of the gender gap in micromobility.

\section{Conclusions}

Gender equity is a very important topic in the transport sector and in micromobility specifically. More synergies, policies and actions are needed so the gap that the present research indicates to be bridged. The present research highlights that the age, the job occupation as well as the perceived safety feeling when using e-scooters can have significant effect on the way women perceive gender equity. Specifically, older women are more likely to feel a narrower gender gap compared to younger women. Additionally, retired women feel a smaller gap compared to the unemployed. Then, uncertainty of e-scooters' safety levels seem to broaden the gender gap.

Concerning future researches, it should be noted that gender impact assessment should be conducted. It is very important in the transport domain to assess every intervention or plan. The present study shed some light in the importance of the gender perspective in mobility and more specific in micromobility. These results may assist micromobility companies to provide gender equal services as well as the competent authorities to enact more coherent policy towards the bridging of the gender gap.

Author Contributions: Conceptualization, T.C. and S.B.; methodology, A.S. and A.K.; software, A.S. and A.K.; validation, A.S. and A.K.; formal analysis, A.S. and A.K.; investigation, T.C. resources, T.C.; data curation, A.S. and A.K.; writing—original draft preparation, A.S., A.K. and T.C.; writing—review 
and editing, A.S., A.K. and S.B.; visualization, T.C.; supervision, S.B.; project administration, T.C. All authors have read and agreed to the published version of the manuscript.

Funding: This research received no external funding.

Institutional Review Board Statement: Ethical review and approval were waived for this study, due to the fact that there was not any requisition or official demand for such a permission.

Informed Consent Statement: Informed consent was obtained from all who were involved in the study.

Data Availability Statement: No new data were created or analyzed in this study. Data sharing is not applicable to this article.

Conflicts of Interest: The authors declare no conflict of interest.

\section{References}

Abduljabbar, Rusul L., Sohani Liyanage, and Hussein Dia. 2021. The role of micro-mobility in shaping sustainable cities: A systematic literature review. Transportation Research Part D: Transport and Environment 92: 102734. [CrossRef]

Almannaa, Mohammed Hamad, Alsahhaf Faisal Adnan Alsahhaf, Huthaifa I. Ashqar, Elhenawy Mohammed, Masoud Mahmoud, and Rakotonirainy Andry. 2021. Perception Analysis of E-Scooter Riders and Non-Riders in Riyadh, Saudi Arabia: Survey Outputs. Sustainability 13: 863. [CrossRef]

Al-Rashid, Muhammad A., Kh M. Nahiduzzaman, Sohel Ahmed, Tiziana Campisi, and Nurten Akgün. 2020. Gender-Responsive Public Transportation in the Dammam Metropolitan Region, Saudi Arabia. Sustainability 12: 9068. [CrossRef]

Anderson, Gordon, Teng Wah Leo, and Robert Muelhaupt. 2009. Qualified Equal Opportunity and Conditional Mobility: Gender Equity and Educational Attainment in Canada. Available online: https://www.economics.utoronto.ca/public/workingPapers /tecipa-368.pdf (accessed on 29 August 2021).

Avineri, Erel, and Fiona Steven. 2013. Has the Introduction of the Cycle-to-Work Scheme Increased Levels of Cycling to Work in the UK? Available online: https://trid.trb.org/view/1241308 (accessed on 29 August 2021).

Bastian, Anne, and Maria Börjesson. 2018. The city as a driver of new mobility patterns, cycling and gender equality: Travel behaviour trends in Stockholm 1985-2015. Travel Behaviour and Society 13: 71-87. [CrossRef]

Beecham, Roger, and Jo Wood. 2014. Exploring gendered cycling behaviours within a large-scale behavioural data-set. Transportation Planning and Technology 37: 83-97. [CrossRef]

Boglietti, Stefania, Benedetto Barabino, and Giulio Maternini. 2021. Survey on e-powered micro personal mobility vehicles: Exploring current issues towards future developments. Sustainability 13: 3692. [CrossRef]

Campisi, Tiziana, Kh Md Nahiduzzaman, Dario Ticali, and Giovanni Tesoriere. 2020a. Bivariate Analysis of the Influencing Factors of the Upcoming Personal Mobility Vehicles (PMVs) in Palermo. In International Conference on Computational Science and Its Applications. Cham: Springer, pp. 868-81.

Campisi, Tiziana, Nurten Akgün, Dario Ticali, and Giovanni Tesoriere. 2020b. Exploring Public Opinion on Personal Mobility Vehicle Use: A Case Study in Palermo, Italy. Sustainability 12: 5460. [CrossRef]

Campisi, Tiziana, Kh Md Nahiduzzaman, Nurten Akgün, Dario Ticali, and Giovanni Tesoriere. 2021a. Gender equality on developing transport system in sicily: A consideration on regional scale. In AIP Conference Proceedings. New York: AIP Publishing LLC.

Campisi, Tiziana, Socrates Basbas, Anastasios Skoufas, Giovanni Tesoriere, and Dario Ticali. 2021b. Socio-Eco-Friendly Performance of E-Scooters in Palermo: Preliminary Statistical Results BT -Innovation in Urban and Regional Planning. Edited by D. La Rosa and R. Privitera. Cham: Springer International Publishing, pp. 643-53.

Campisi, Tiziana, Socrates Basbas, Anastasios Skoufas, Giovanni Tesoriere, and Dario Ticali. 2021c. Socio-Eco-Friendly Performance of E-Scooters in Palermo: Preliminary Statistical Results. Innovation in Urban and Regional Planning, 643-53.

Carrese, Stefano, Fabio D'Andreagiovanni, Tommaso Giacchetti, Antonella Nardin, and Leonardo Zamberlan. 2021. A beautiful fleet: Optimal repositioning in e-scooter sharing systems for urban decorum. Transportation Research Procedia 52: 581-88. [CrossRef]

Cinti, di Giulia. The Space of Women in the City: How the Gender Data Gap Has Eliminated It. Available online: https://www.trecca ni.it/magazine/chiasmo/diritto_e_societa/Spazio/SSSGL_Cinti_Trip-Chaining.html (accessed on 17 August 2021).

Curreli, di Alessandra. Monopattino re della Mobilità. Available online: https://www.trend-online.com/risparmio/monopattino-r e-della-mobilita / (accessed on 17 August 2021).

Damyanovic, Doris, Florian Reinwald, and Angela Weikmann. 2013. Manual for Gender Mainstreaming in Urban Planning and Urban Development. Available online: https://www.wien.gv.at/stadtentwicklung/studien/pdf/b008358.pdf (accessed on 10 August 2021).

Daniel, Wayne W., and Chad L. Cross. 1999. Biostatistics: A Foundation for Analysis in the Health Sciences, 7th ed. Hoboken John: Wiley \& Sons, Ltd.

De Ceunynck, Tim, Gert J. Wijlhuizen, Aslak Fyhri, Regine Gerike, Dagmar Köhler, Alice Ciccone, Atze Dijkstra, Emmanuelle Dupont, and Mario Cools. 2021. Assessing the Willingness to Use Personal e-Transporters (PeTs): Results from a Cross-National Survey in Nine European Cities. Sustainability 13: 3844. [CrossRef] 
European Commission Women in Transport-EU Platform for Change. n.d. Available online: https:/ /ec.europa.eu/transport/themes/ social/women-transport-eu-platform-change_en (accessed on 10 August 2021).

European Institute for Gender Equality (EIGE) Covid-19 and Gender Equality. n.d.-a. Available online: https://eige.europa.eu/ (accessed on 17 August 2021).

European Institute for Gender Equality (EIGE) Covid-19 and Gender Equality (Italy). n.d.-b. Available online: https://eige.europa.eu / countries/italy (accessed on 17 August 2021).

Färber, Christine. 2011. Gender in local public transport planning. In Gender in Mainstreaming Urban Development. Available online: https:/ / civitas.eu/sites/default/files/berlin_gender_mainstreaming_0.pdf (accessed on 17 August 2021).

Georgiou, Aggelos, Anastasios Skoufas, and Socrates Basbas. 2021. Perceived Pedestrian Level of Service in an urban central network: The case of a medium size Greek city. Case Studies on Transport Policy 9: 889-905. [CrossRef]

Glavić, Draženko, Ana Trpković, Marina Milenković, and Sreten Jevremović. 2021. The E-Scooter Potential to Change Urban Mobility-Belgrade Case Study. Sustainability 13: 5948. [CrossRef]

González-Sánchez, Guadalupe, María Isabel Olmo-Sánchez, and Elvira Maeso-González. 2021. Challenges and Strategies for PostCOVID-19 Gender Equity and Sustainable Mobility. Sustainability 13: 2510. [CrossRef]

Grudgings, Nick, Alex Hagen-Zanker, Susan Hughes, Birgitta Gatersleben, Marc Woodall, and Will Bryans. 2018. Why don't more women cycle? An analysis of female and male commuter cycling mode-share in England and Wales. Journal of Transport $\mathcal{E}$ Health 10: 272-83. [CrossRef]

Habitat, Un. 2018. Report on Gender Equity Assessment of Nairobi's Public Minibus Transport Services. Available online: https: / / floneinitiative.org/wp-content/uploads/2019/05/GEA-Report.pdf (accessed on 10 August 2021).

Hail, Yvonne, and Ronald McQuaid. 2021. The Concept of Fairness in Relation to Women Transport Users. Sustainability 13: 2919. [CrossRef]

Hanson, Susan. 2010. Gender and mobility: New approaches for informing sustainability. Gender Place E Culture 17: 5-23.

Hardt, Cornelius, and Klaus Bogenberger. 2019. Usage of e-Scooters in Urban Environments. Transportation Research Procedia 37: 155-62. [CrossRef]

He, Yi, Ziqi Song, Zhaocai Liu, and N.N. Sze. 2019. Factors Influencing Electric Bike Share Ridership: Analysis of Park City, Utah. Transportation Research Record 2673: 12-22. [CrossRef]

Heesch, Kristiann C., Shannon Sahlqvist, and Jan Garrard. 2012. Gender differences in recreational and transport cycling: A crosssectional mixed-methods comparison of cycling patterns, motivators, and constraints. International Journal of Behavioral Nutrition and Physical Activity 9: 106. [CrossRef]

Herrera, Lázaro Moreno. 2007. Equity, equality and equivalence: A contribution in search for conceptual definitions and a comparative methodology. Revista Española de Educación Comparada 13: 319-40.

Hosseinzadeh, Aryan, Majeed Algomaiah, Robert Kluger, and Zhixia Li. 2021. E-scooters and sustainability: Investigating the relationship between the density of E-scooter trips and characteristics of sustainable urban development. Sustainable Cities and Society 66: 102624. [CrossRef]

International Transport Forum. 2020. Safe Micromobility. Available online: https:/ /www.itf-oecd.org/safe-micromobility (accessed on 17 August 2021).

James, Owain, J I. Swiderski, John Hicks, Denis Teoman, and Ralph Buehler. 2019. Pedestrians and E-Scooters: An Initial Look at E-Scooter Parking and Perceptions by Riders and Non-Riders. Sustainability 11: 5591. [CrossRef]

Jennings, Gail, Rahul Jobanputra, Cpnstant Cap, Genevivie Ankunda, and S. Mugume. 2021. Learning from COVID-19 Pop-Up Bicycle Infrastructure: An Investigation into Flexible and User-Led Bicycle Planning in Cape Town, Nairobi, and Kampala. Available online: https://www.researchgate.net/publication/349806055_FINAL_REPORT_Learning_from_COVID-19_pop-up_bicycle_in frastructure_an_investigation_into_flexible_and_user-led_bicycle_planning_in_Cape_Town_Nairobi_and_Kampala (accessed on 18 August 2021).

Jiao, Junfeng, and Shunhua Bai. 2020. Understanding the Shared E-scooter Travels in Austin, TX. ISPRS International Journal of Geo-Information 9: 135. [CrossRef]

Kostareli, Athanasia, Socrates Basbas, Nikiforos Stamatiadis, and Andreas Nikiforiadis. 2020. Attitudes of E-Scooter Non-users towards Users. In Advances in Mobility-as-a-Service Systems. New York: Springer, pp. 87-96. ISBN 978-3-030-61074-6.

Kraus, Sebastian, and Nicolas Koch. 2021. Provisional COVID-19 infrastructure induces large, rapid increases in cycling. Proceedings of the National Academy of Sciences 118. [CrossRef]

Kronsell, Annica, Lena Smidfelt Rosqvist, and Lena Winslott Hiselius. 2016. Achieving climate objectives in transport policy by including women and challenging gender norms: The Swedish case. International Journal of Sustainable Transportation 10: 703-11. [CrossRef]

Laa, Barbara, and Ulrich Leth. 2020. Survey of E-scooter users in Vienna: Who they are and how they ride. Journal of Transport Geography 89: 102874. [CrossRef]

Lecompte, María Carolina, and Bocarejo S. Juan Pablo. 2017. Transport systems and their impact con gender equity. Transportation Research Procedia 25: 4245-257. [CrossRef]

Leung, Tak Yan, Piyush Sharma, Pattarin Adithipyangkul, and Peter Hosie. 2020. Gender equity and public health outcomes: The COVID-19 experience. Journal of Business Research 116: 193-98. [CrossRef] [PubMed] 
Madapur, Bhagyalaxmi, Shilpa Madangopal, and M. N. Chandrashekar. 2020. Micro-Mobility Infrastructure for Redefining Urban Mobility. European Journal of Engineering Science and Technology 3: 71-85. [CrossRef]

Marzulli, M. The Impressive Numbers of Micro-Mobility in Italy. Available online: https:/ /www.fleetmagazine.com/numeri-micro mobilita-italia/ (accessed on 18 August 2021).

McKenzie, Grant. 2019. Shared micro-mobility patterns as measures of city similarity. Paper presented at the 1st ACM SIGSPATIAL International Workshop on Computing with Multifaceted Movement Data-MOVE'19, Chicago, IL, USA, November 5.

McKenzie, Grant. 2019. Spatiotemporal comparative analysis of scooter-share and bike-share usage patterns in Washington, D.C. Journal of Transport Geography 78: 19-28. [CrossRef]

Milan, Blanca Fernandez, and Felix Creutzig. 2017. Lifting peripheral fortunes: Upgrading transit improves spatial, income and gender equity in Medellin. Cities 70: 122-34. [CrossRef]

Mishra, Anurag, Priya Nanda, Ilene S. Speizer, Lisa M. Calhoun, Allison Zimmerman, and Rochak Bhardwaj. 2014. Men's attitudes on gender equality and their contraceptive use in Uttar Pradesh India. Reproductive Health 11: 1-13.

Mitra, Raktim, and Paul M. Hess. 2021. Who are the potential users of shared e-scooters? An examination of socio-demographic, attitudinal and environmental factors. Travel Behaviour and Society 23: 100-7. [CrossRef]

Morley, Louise. 2005. Gender equity in Commonwealth higher education. In Women's Studies International Forum. Pergamon: Elsevier, vol. 28, pp. 209-21. [CrossRef]

Mukaka, M. M. 2012. Statistics corner: A guide to appropriate use of correlation coefficient in medical research. Malawi Medical Journal: The Journal of Medical Association of Malawi 24: 69-71. [CrossRef]

Naing, L., T. Winn, and B. N. Rusli. 2006. Practical Issues in Calculating the Sample Size for Prevalence Studies. Available online: https:/ / d1wqtxts1xzle7.cloudfront.net/44372553/09_14_Ayub-with-cover-page-v2.pdf?Expires=1634535280\&Signature=L $\sim\{\}$ HYlCfV2TDXWUB \{\}ptOzABP-Rn3HTVD-1HIDIbSV8RmB8aH2F3ibdgJDIT \{ \{\}VAmOZlij9Dbt0robpVH3NW5tuOwJuMvf JNKG \{\}0C6AMGmoRsHnA7WmBrrf6brPLTqo3LNEp932r9usITBC5foL7kBstqg9uTWui5MH \{\}6iUKtffJrn99161Tg6nZc8xuX IF4xMNOg5OBJyNwrnW-BnctCeYa1ldWDDs0n8hH7t4ZjPUyQnKgA0r \{\}GwK6K0DSxRZVqHjRgVV97f8aojDQcbK35rvlzm Nttw5K2Eda2eMpO14wwzlLvRCPzP2bBQU5ncdldT3Wyx3 \{\}Ea9m6MEUDms0rNz7Q_\&Key-Pair-Id=APKAJLOHF5GGS LRBV4ZA (accessed on 18 August 2021).

Nerén, Dan. n.d. Swedish Cities Would Benefit from Clearer Micro-Mobility Rules. Available online: https://www.tier.app/swedish -cities-would-benefit-from-clearer-micro-mobility-rules/ (accessed on 18 August 2021).

Nikiforiadis, Andreas, and Socrates Basbas. 2019. Can pedestrians and cyclists share the same space? The case of a city with low cycling levels and experience. Sustainable Cities and Society 46: 101453. [CrossRef]

Nikiforiadis, Andreas, Evangelos Paschalidis, Nikiforos Stamatiadis, Alexandra Raptopoulou, Athanasia Kostareli, and Socrates Basbas. 2021. Analysis of attitudes and engagement of shared e-scooter users. Transportation Research Part D: Transport and Environment 94: 102790. [CrossRef]

Oeschger, Giulia, Páraic Carroll, and Brian Caulfield. 2020. Micromobility and public transport integration: The current state of knowledge. Transportation Research Part D: Transport and Environment 89: 102628. [CrossRef]

Orozco-Fontalvo, Mauricio, José Soto, Andrea Arévalo, and Oscar Oviedo-Trespalacios. 2019. Women's perceived risk of sexual harassment in a Bus Rapid Transit (BRT) system: The case of Barranquilla, Colombia. Journal of Transport E Health $14: 100598$.

Ouali, Laila Ait Bihi, Daniel J. Graham, Alexander Barron, and Mark Trompet. 2020. Gender differences in the perception of safety in public transport. Journal of the Royal Statistical Society: Series A (Statistics in Society) 183: 737-69. [CrossRef]

Pirra, Miriam, Sofia Kalakou, Angela Carboni, Mariana Costa, Marco Diana, and Ana R. Lynce. 2021. A preliminary analysis on gender aspects in transport systems and mobility services: Presentation of a survey design. Sustainability 13: 2676. [CrossRef]

Pozoukidou, G., and Z. Chatziyiannaki. 2021. 15-Minute City: Decomposing the New Urban Planning Eutopia. Sustainability 13: 928. [CrossRef]

Raptopoulou, Alexandra, Socrates Basbas, Nikiforos Stamatiadis, and Andreas Nikiforiadis. 2020. A First Look at E-Scooter Users. In Advances in Mobility-as-a-Service Systems. New York: Springer, pp. 882-91. ISBN 978-3-030-61074-6.

Sagaris, Lake, and Ignacio Tiznado-Aitken. 2018. Walking and Gender Equity: Insights from Santiago Chile (No. 18-05195). Available online: https:/ / trid.trb.org/view/1496637 (accessed on 18 August 2021).

Sallah, Cynthia Ayorkor, and Livingstone Divine Caesar. 2020. Intangible resources and the growth of women businesses: Empirical evidence from an emerging market economy. Journal of Entrepreneurship in Emerging Economies 12. [CrossRef]

Scorrano, Mariangela, and Romeo Danielis. 2021. The characteristics of the demand for electric scooters in Italy: An exploratory study. Research in Transportation Business \& Management 39: 100589.

Shaheen, Susan, and Adam Cohen. 2020. Mobility on demand (MOD) and mobility as a service (MaaS): Early understanding of shared mobility impacts and public transit partnerships. In Demand for Emerging Transportation Systems. Amsterdam: Elsevier, pp. 37-59.

Sharp, Sonja. 2019. Cities Use Invisible Geofencing to Control Use of E-Scooters. Available online: https://www.govtech.com/transp ortation/ cities-use-invisible-geofencing-to-control-use-of-e-scooters.html (accessed on 10 August 2021).

Sokolowski, M.M. 2020. Laws and Policies on Electric Scooters in the European Union: A Ride to the Micromobility Directive? European Energy and Environmental Law Review 29.

Statistica, I.N. 2021. di The Permanent Census of the Population in Sicily. Available online: https://www.istat.it/it/archivio/253856\#: $\sim\{\}:$ text=LapopolazionecensitainSicilia, anno)rispettoalCensimento2011 (accessed on 18 August 2021).

Tomassi, Federico. 2018. Il Trasporto Pubblico Locale: Confronto tra Roma. Milano: Napoli e Torino. 
Tuncer, Sylvaine, and Barry Brown. 2020. E-scooters on the ground: Lessons for redesigning urban micro-mobility. Paper presented at the 2020 CHI Conference on Human Factors in Computing Systems, Honolulu, HI, USA, April 25-30; pp. 1-14.

Tuncer, Sylvaine, Eric Laurier, Barry Brown, and Christian Licoppe. 2020. Notes on the practices and appearances of e-scooter users in public space. Journal of Transport Geography 85: 102702. [CrossRef]

Twisse, Fiona. 2021. Overview of Policy Relating to E-Scooters in European Countries. Available online: https://www.eltis.org/reso urces/case-studies/overview-policy-relating-e-scooters-european-countries (accessed on 17 August 2021).

Umaña-Barrios, Nancy, and Andrea San Gil. 2017. How Can Spatial Design Promote Inclusivity, Gender Equality and Overall Sustainability in Costa Rica's Urban Mobility System? Procedia Engineering 198: 1018-35. [CrossRef]

United Nations. n.d. Goal 5: Achieve Gender Equality and Empower All Women and Girls. Available online: https://www.un.org/s ustainabledevelopment/gender-equality / (accessed on 17 August 2021).

Uteng, Tanu Priya. 2012. Gender and Mobility in the Developing World. Available online: https://openknowledge.worldbank.org/ handle/10986/9111 (accessed on 10 August 2021).

Vecchio, Giovanni, Ignacio Tiznado-Aitken, and Ricardo Hurtubia. 2020. Transport and equity in Latin America: A critical review of socially oriented accessibility assessments. Transport Reviews 40: 354-81. [CrossRef]

Weinreich, Marianne. 2021. Ramboll Smart Mobility Gender and (Smart) Mobility. Available online: https://barracudaex.aub.aau.dk /index.php/td/article/view/ 6929 (accessed on 18 August 2021).

Yatskiv, Irina, and Nadezda Spiridovska. 2013. Application of ordinal regression model to analyze service quality of Riga coach terminal. Transport 28: 25-30. [CrossRef]

Zagorskas, Jurgis, and Marija Burinskienè. 2020. Challenges Caused by Increased Use of E-Powered Personal Mobility Vehicles in European Cities. Sustainability 12: 273. [CrossRef] 